University of Nebraska - Lincoln

DigitalCommons@University of Nebraska - Lincoln

2016

\title{
Phylogeny and biogeography of species of Syphacia Seurat, 1916 (Nemata : Oxyurida : Oxyuridae) from the Australian Bioregion
}

Haylee J. Weaver

Australian Biological Resources Study, weaver.haylee@gmail.com

Scott Monks

Universidad Autónoma del Estado de Hidalgo, monks.scott@gmail.com

Scott Gardner

University of Nebraska - Lincoln, slg@unl.edu

Follow this and additional works at: https://digitalcommons.unl.edu/slg

Part of the Biodiversity Commons, Biology Commons, Ecology and Evolutionary Biology Commons, and the Parasitology Commons

Weaver, Haylee J.; Monks, Scott; and Gardner, Scott, "Phylogeny and biogeography of species of Syphacia Seurat, 1916 (Nemata : Oxyurida : Oxyuridae) from the Australian Bioregion" (2016). Scott Gardner Publications \& Papers. 23.

https://digitalcommons.unl.edu/slg/23

This Article is brought to you for free and open access by the Parasitology, Harold W. Manter Laboratory of at DigitalCommons@University of Nebraska - Lincoln. It has been accepted for inclusion in Scott Gardner Publications \& Papers by an authorized administrator of DigitalCommons@University of Nebraska - Lincoln. 


\title{
Phylogeny and biogeography of species of Syphacia Seurat, 1916 (Nemata : Oxyurida : Oxyuridae) from the Australian Bioregion
}

\author{
Haylee J. Weaver, ${ }^{1,2}$ Scott Monks, ${ }^{3}$ and Scott L. Gardner ${ }^{4}$
}

1 School of Science and Engineering, University of the Sunshine Coast, Sippy Downs, Qld 4556, Australia

2 Present address: Australian Biological Resources Study, Department of the Environment, GPO Box 787, Canberra, ACT 2601, Australia

3 Universidad Autónoma del Estado de Hidalgo (UAEH), Centro de Investigaciones

Biológicas (CIB), Apdo. Postal 1-10, Pachuca, C.P. 42001, Hidalgo, México

4 Manter Laboratory of Parasitology, University of Nebraska State Museum and School of

Biological Sciences, University of Nebraska - Lincoln, Lincoln, NE 68588-0514, USA

Corresponding author - H. J. Weaver, email haylee.weaver@environment.gov.au

\begin{abstract}
.
Pinworm nematodes of the genus Syphacia (Nemata : Oxyurida : Oxyuridae) have a global distribution, and infect the caecum of rodents. Within the Australian Bioregion, 17 species of Syphacia infect a range of rodent hosts. Pinworms are traditionally thought to have coevolutionary relationships with their hosts, but the evolution and dispersal of Australian rodents and their helminths remains unclear. This combination of factors allowed us to investigate the likely relationships of Australian Syphacia species based on phylogenetic analysis, overlaid with the ecology and
\end{abstract}

Published in Australian Journal of Zoology, 2016, 64, 81-9o.

http://dx.doi.org/10.1071/ZO15080

Journal compilation (C) 2016 CSIRO. Used by permission.

Submitted 2 December 2015; accepted 10 May 2016, published 17 June 2016. 
relationships of host species. We conducted a phylogenetic analysis using morphological characters of the species of Syphacia from the Australian Bioregion in order to examine the relationships between species, and to investigate how host evolution and phylogeny could inform (or be informed) by parasite phylogeny. Application of the taxon pulse theory of parasite speciation by matching host species to parasites shed some light on the timing of speciation of rodent hosts. We found that species of Syphacia had reasonably close host-parasite relationships, with additional evidence for ecological fitting or host switching occurring. Evidence provided here suggests strongly that most elements of the Stockholm Paradigm are at play in structuring the relationships we observe in this pinworm-mammal system.

\section{Introduction}

Pinworm nematodes (Oxyurida : Oxyuridae) infect the posterior gut of vertebrates (Adamson 1994; Anderson 2000). Species of Oxyuridae have direct life-cycles, a haplo-diploid life history (haploid males and diploid females), and typically a high degree of host specificity (Adamson 1994; Sorci et al. 1997). Within the Oxyuridae, the subfamily Syphaciinae comprises five tribes, all recorded from rodents and lagomorphs (Adamson 1994; Hugot et al. 1996). The Syphaciini, considered to be the most recent and speciose of the five tribes, is thought to have arisen during the Miocene in the Rodentia of Asia, dispersing to Africa, North America, and Australia with their rodent hosts (Hugot 1988; Adamson 1994). The diversity of the Oxyuridae presents an opportunity to explore the evolution, phylogeny and systematics of this group, but research in this area has been restricted mainly to those species that are parasites of primates (Oxyurinae, Enterobiinae) (see Hugot et al. 1996; Sorci et al. 1997; Hugot 1999). Coevolution, as a mechanism for oxyurid speciation, was first suggested by Cameron (1929) following observations of the great host specificity of oxyurids in primates (see review by Hugot 1999). While this hypothesis seems to have held for parasites of primates (Sorci et al. 1997; Hugot 1999; Brooks and McLennan 2003), patterns of speciation and evolution of the oxyurids of rodents (squirrels, rats, and mice) is less clear (Hugot 1999). There are few studies on the systematics and phylogenetic relationships of Syphaciinae, and none that have included Australian endemic species other than S. darwini Hugot \& Quentin, 1985 (see Hugot 1988, 1990; Hugot et al. 2013). 
Species of Syphacia Seurat, 1916, the focus of the present study, have a cosmopolitan distribution in rodents (Quentin 1971; Petter and Quentin 1976; Hugot 1988). They are characterized by having three mamelons on the ventral surface of the male and, in both sexes, identical cephalic structures close to the amphids (Petter and Quentin 1976). At the time of Hugot's (1988) analysis, only S. muris (Yamaguti 1935) and $S$. darwini were known from Australia. The cosmopolitan species $S$. muris occurs as a regular parasite of the similarly cosmopolitan Rattus rattus (Linnaeus, 1758) and $R$. norvegicus (Berkenhout, 1769). However, $S$. muris has also been recorded from the Australian endemic species $R$. tunneyi (Thomas, 1904), R. fuscipes (Waterhouse, 1839), and $R$. sordidus (Gould, 1858) (see Hugot and Quentin 1985; Hugot 1988; Smales 1992, 1997), and R. xanthurus (Gray, 1867), endemic to Sulawesi (Hasegawa and Tarore 1996). Since the initial study of Hugot (1988), 15 additional species from the Australian Bioregion have been described. Of the total 16 endemic species known from the region, six are known only from Australia (Weaver and Smales 2006, 2008, 2010), two occur in both New Guinea and Australia (Hugot and Quentin 1985; Smales 1997, 2004, 2005), and four of these pinworms are restricted to New Guinea (Smales 2001, 2009, 2010, 2011; Smales and Spratt 2008). Four other species occur in Sulawesi, Indonesia (Dewi and Hasegawa 2010, 2014; Hasegawa and Tarore 1996), but are included in this analysis because their distribution is part of the Australian biogeographic region.

The Australian biogeographic region includes the islands of the Indonesian archipelago west from New Guinea to Wallace's Line, the Australian landmass, and the island of New Guinea. Wallace's Line, running north-south between Borneo and Sulawesi, and between Bali and Lombok, is the traditionally accepted junction between the Australian and South-East Asian flora and fauna (Sclater 1858; Wallace 1876; Cox 2001). More recently, using data based on the analysis of the phylogenetics of vertebrates, Holt et al. (2013) identified Australia as a zoogeographic bioregion separately, with New Guinea and some Indonesian islands becoming the Oceania Bioregion and Sulawesi becoming part of the Oriental Bioregion.

The rodent genus Rattus occurs in suitable habitats across both the entire Asian (Oriental), Oceania, and Australian Bioregions, but species of many other genera of rodents are highly specific to particular 
regions and many have limited allopatric distributions occurring in geographically restricted areas. The current distributions of plants and animals in these areas has been attributed to differential/complex accretion phases of the northern part of New Guinea, resulting in the development of a complex mosaic of species (van Welzen et al. 2001). For completeness, in this study we will include Syphacia species from Australia, New Guinea and Sulawesi, to Wallace's Line.

The phylogenetic and biogeographic relationships among rodents of the Australian Bioregion are not yet fully resolved. Australian endemic rodents (Rodentia : Muridae : Murinae) fall into two distinct categories - the 'old endemic' rodents and the 'new endemic' rodents (Watts and Aslin 1981). The old endemics comprise one Australo-Papuan tribe, the Hydromyini, and the new endemics are part of the tribe Rattini (see Lecompte et al. 2008; Van Dyck and Strahan 2008). There is conjecture over the timing and number of migration/colonization events of the old endemic genera, with Rowe et al. (2008) estimating up to nine dispersal events between New Guinea and Australia, using a dispersal-vicariance model. The two groups, the Hydromyini and the Rattini, are thought to have diverged around 9.7 million years ago (Robins et al. 2010). Species of the Hydromyini are thought to have a mixed origin, with the 'conilurin' group (including Pseudomys and Zyzomys) considered to have originated in Australia, diverging 6.5-7.2 million years ago (Rowe et al. 2008; Nilsson et al. 2010), with little colonization northward to New Guinea. Pseudomys delicatulus (Gould, 1842) is the only member with a distribution in New Guinea, and has been recorded from only one locality in Western Province, Papua New Guinea (Flannery 1995). In contrast to the conilurin group, species of the tribe referred to as the 'uromyin' group (Melomys, Uromys and Lorentzimys) are thought to have diverged and diversified in New Guinea, with subsequent later dispersal to Australia (Long et al. 2002; Rowe et al. 2008; Bryant et al. 2011). These movements and dispersal events of the conilurin and uromyin groups were followed in space and time by species of Rattus, with Asian and Australo-Papuan clades that diverged around 2.7 million years ago, with subsequent divergence of the Australo-Papuan clade into at least four lineages around 0.9-1.7 million years ago (Robins et al. 2010). The genus Rattus is currently represented in Australia by eight endemic species. In Australia, $R$. rattus, $R$. norvegicus, and 
M. musculus (and their parasite $S$. muris) are synanthropic and were introduced in the late 1700 s.

One hypothesis holds that the current distribution of rodents and (by association) their parasites could be indicative of pulses of colonization and subsequent speciation of parasites and their hosts (= taxon pulses sensu Erwin 1985; Halas et al. 2005; Hoberg and Brooks 2010) that have resulted in the patterns of events inferred from the fossil record. Ecological fitting (EF) occurs when parasites switch to the same niche space in a new species of host. Switching to a new host but utilizing the same shared plesiomorphic resource (in the case of Syphacia, the caecum), means that the parasite species can form a new association with very little evolutionary effort (Janzen 1985; Brooks and McLennan 2002; Brooks et al. 2006). Work by Hoberg and Brooks (2010) and Halas et al. (2005) has shown that hypotheses of taxon pulses and EF often can explain the patterns of distribution of taxa and that these processes are the primary drivers of geographic diversity in many, if not most, host-parasite systems. Furthermore, both the taxon pulse and EF hypotheses comprise part of a broader framework for understanding host-parasite evolution: the Stockholm Paradigm (see Brooks et al. 2014, 2015; Hoberg and Brooks 2015). The framework also includes the hypotheses of the geographic mosaic theory of coevolution (Thompson 2005), and the oscillation hypothesis (see Janz and Nylin 2008). The Stockholm Paradigm serves as a conceptual foundation for the study of host-parasite systems in an historical ecological sense. As noted above, our study shows the potential for at least EF and taxon pulses (Erwin 1985) to play an important role in the diversification of these nematodes and their host species. In order to study the processes of evolutionary ecology in helminths essentially non-existent in the fossil record, we must first reconstruct the phylogeny of these helminths, based on the evolution of characters of present-day species, and compare this with the patterns of speciation and evolution of their hosts. The aim of our study was to propose a phylogenetic hypothesis for species of Syphacia present in the Australo-Papuan region (as part of the Australian Bioregion), and to examine comparatively the biogeography of species of Syphacia and their rodent hosts in this region. 


\section{Materials and methods}

We compiled a data matrix from comparative morphological analysis of 24 characters (see list in Results) derived from study of 17 species of Syphacia (Table 1). We selected characters (e.g. shape of cephalic plate, presence of alae, etc.) that are characteristic of the genus and diagnostic for determining species, and also based on those used previously by other workers (see Hugot 1988; Hugot et al. 2013). We included additional mensural characters to increase the robustness of the dataset. The number of specimens per species examined varied due to available material. No a priori designation of character states was used. The tree was rooted using one outgroup (S. muris), a species with a cosmopolitan distribution found in murid rodents, and introduced into the areas of the Australian Bioregion along with its hosts (commonly Mus and Rattus spp.). The in-group includes all known (up to year 2014) species of Syphacia from the Australian Bioregion. Character analysis was based on morphology of each species described in the literature, and via direct study of specimens with light or scanning electron microscopy. All measurements were made in micrometers, unless specified otherwise. No molecular sequences yet exist for the species of Syphacia in the in-group, so molecular data were not included in the dataset.

Quantitative and qualitative characters were used for the phylogenetic analysis. These data were taken directly from specimens we examined ( $S$. abertoni $[n=20]$, $S$. darwini $[n=8]$, S. longaecauda [ $n$ $=20]$, S. pseudomyos $[n=27]$, S. brevicaudata $[n=25]$, S. carnarvonensis $[n=20], S$. helidonensis $[n=15]$, S. boodjamullaensis $[n=$ $20]$, S. muris $[n=10]$ ), and from species descriptions where necessary. Data values from the literature consisted of means, ranges, and maximum values; standard deviations for some measurements were taken from the literature. For the quantitative characters, if only a mean value was given in the literature, the value was considered to be both the minimum and maximum of the interval. When a standard deviation was included with the mean value the interval was calculated following Sokal and Rohlf (1981). Interval data points for each character were inserted directly into the matrix. When only maximum values were given, this value was converted to an interval with that value used as both minimum and maximum. To ensure that all 


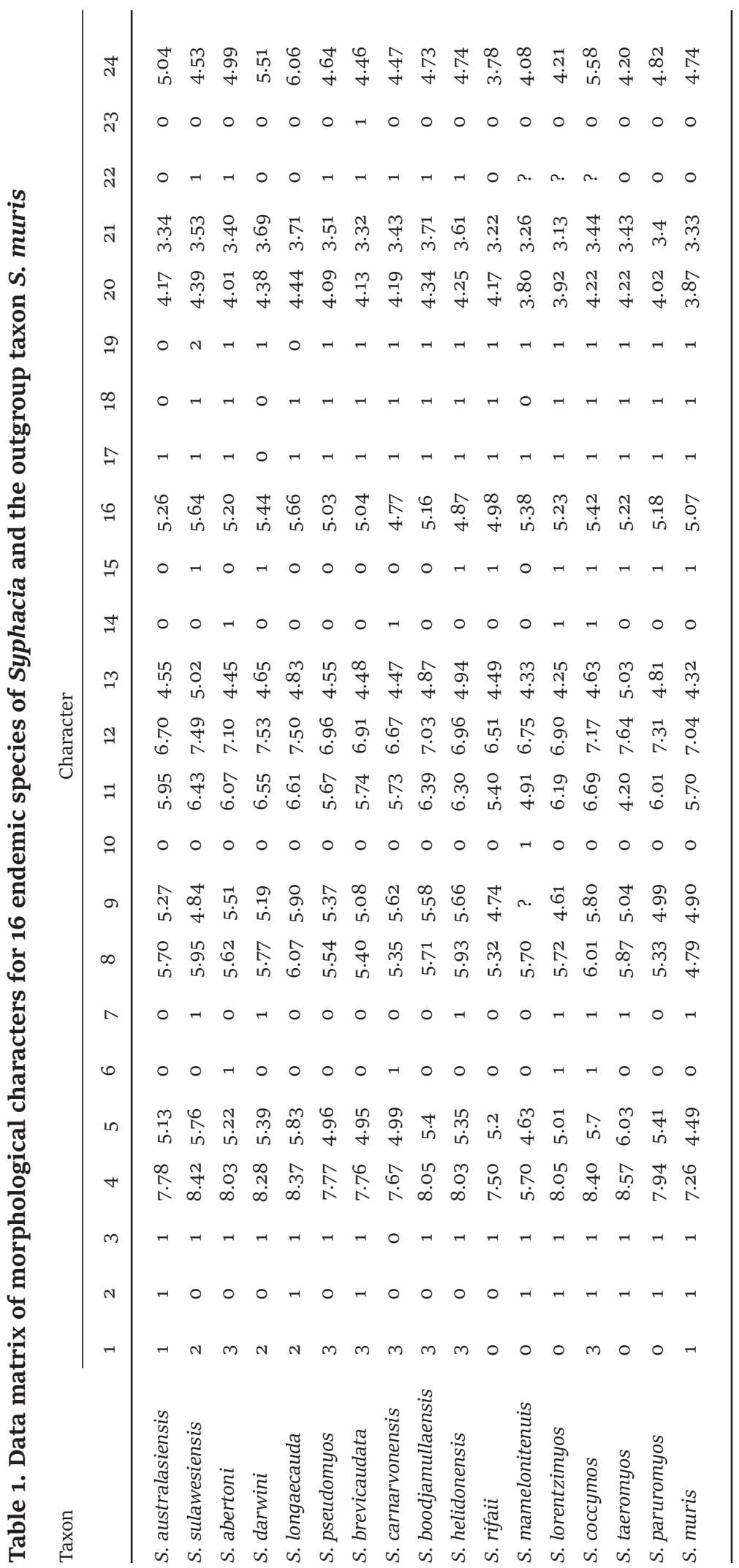


values were normally distributed, all measurements were $\log _{n}$-transformed before analysis (see matrix in Table 1). We used the program TNT 1.1 (Goloboff et al. 2008) for all phylogenetic analyses. Character states were polarized by outgroup comparison (Watrous and Wheeler 1981), referring to $S$. muris as the outgroup. Missing data were coded '?', all characters were weighted equally, and were run as non-additive. Parsimony analysis was performed on the data matrix (Table 1) using implicit enumeration (which guarantees that the shortest tree is found) in TNT. To test the results of the implicit enumeration tree, a New Technology search, with default settings of Ratchet and Drift disabled, was run and this gave the same shortest tree. To examine the level of support for each of the branches, both Bremer supports were calculated and bootstrap resampling was run using TNT. To investigate the potential origin and diversification of species of Syphacia in this area, Farris optimization (Farris 1970) was performed on the single most parsimonious tree. For specific examples of this method, see Farris (1970) and Brooks and McLennan (2002). We used the geographic areas from which each species of Syphacia is known or from where it was collected.

\section{Results}

Character states

General

1. Cephalic plate: o, round; 1, quadrangular; 2, oval; 3, laterally stretched. The mouth of Syphacia species is surrounded by a cuticularized plate of varying shapes. The morphology of the plate can be viewed en face, or by scanning electron microscopy (SEM).

2. Amphids: 0 , medial on plate; 1 , lateral on plate. Amphids on the cephalic plate are positioned on each side of the oral opening. Their position was evaluated based on the distance between the mouth and the lateral edge of the cephalic plate.

3. Excretory pore: o, anterior to esophageal bulb; 1, posterior to esophageal bulb. The excretory pore is situated on the ventral surface of Syphacia spp. and can be viewed via light microscopy or SEM. 
Characters of females

4. Body length: measurement (mean of specimens previously examined) given in ln-transformed values.

5. Body width: measurement (mean of specimens previously examined) given in ln-transformed values.

6. Cervical alae: o, absent; 1, present. Cervical alae are present on many nematode taxa. For species of Syphacia, cervical alae are very obvious protrusions of cuticle running down the sides of the worm. Cervical alae usually commence posterior to the cephalic vesicle, and terminate around the site of the excretory pore. They are visible using light microscopy or SEM.

7. Lateral alae: o, absent; 1 , present. As above, lateral alae are cuticular protrusions running the length of the sides of the midbody of worms. They are usually shallower in height from the body wall compared with cervical alae, and are therefore often found only following observations of transverse sections of specimens using light microscopy, or via SEM.

8. Length of esophagus: measurement (mean of specimens previously examined) given in ln-transformed values. Esophagus length was measured using light microscopy, from the anterior end (mouth) to the top of the esophageal bulb.

9. Distance between excretory pore and vulva: measurement (mean of specimens previously examined) given in ln-transformed values. The excretory pore is anterior to the vulva, but the distance between the two can be variable between species. The distance was measured using a light microscope.

10. Cuticle morphology of vulva: 0 , flat (continuous) with cuticle; 1 , raised, projected from cuticle. The tissue surrounding the vulva of some species of oxyurids can be raised, and cause the cuticle to be raised conically around the vulva.

11. Tail length: measurement (mean of specimens previously examined) given in ln-transformed values. Tail lengths were measured from the end of the body cavity, where the tail is formed of cuticle only, as viewed using light microscopy.

\section{Characters of males}

12. Body length: measurement (mean of specimens previously examined) given in ln-transformed values. Body length was 
measured using light microscopy. It was measured from the anterior tip of the cephalic plate to the tip of the tail.

13. Body width: measurement (mean of specimens previously examined) given in ln-transformed values. Body width was measured at the mid-body, defined as halfway down the length of the body. It was measured using light microscopy.

14. Cervical alae: o, absent; 1, present. Cervical alae are present on many nematode taxa. For species of Syphacia, cervical alae are very obvious protrusions of the cuticle running down the sides of the worm. Cervical alae usually commence posterior to the cephalic vesicle, and terminate around the level of the excretory pore. They are visible using light microscopy or SEM.

15. Lateral alae: o, absent; 1, present. As above, lateral alae are cuticular protrusions running the length of the sides of the midbody of worms. They are usually shallower in height from the body wall compared with cervical alae, and often are found only by observation of transverse sections of specimens using light microscopy, or via SEM.

16. Length of esophagus: measurement (mean of specimens previously examined) given in ln-transformed values.

17. Number of mamelons: o, two mamelons; 1 , three mamelons. Species of Syphacia and other oxyurids have raised swellings of cuticle on the ventral surfaces of males. It is thought that it assists with gripping the female during mating. These are visible via light microscopy or SEM.

18. Shape of spicule: o, body curved ventrally; 1 , body straight. The spicule is used for insemination of females, and is found in the posterior end of the male's body cavity. As it is internal, it can be seen via light microscopy.

19. Shape of spicule tip: o, tip rounded; 1 , tip sharp.

20. Spicule length: measurement (mean of specimens previously examined) given in ln-transformed values. Measured using light microscopy.

21. Gubernaculum length: measurement (mean of specimens previously examined) given in ln-transformed values. The gubernaculum is associated with the spicule, and is viewed using light microscopy.

22. Cuticular thickening around cloaca: o, absent; 1, present. In 
some male oxyurids, a cloacal plate is observed, with the cuticle surrounding the cloaca becoming thicker, and in some cases, with raised chitinous contours. It was observed using light microscopy or SEM.

23. Caudal papillae: o, one pair; 1, two pairs. Caudal papillae are large protrusions on either side of the tail. They are visible using light microscopy and SEM.

24. Tail length: measurement (mean of specimens previously examined) given in ln-transformed values.

Phylogenetic analysis

Analysis of the data matrix produced a single tree 44.356 steps long with a consistency index of 0.521 , and a retention index of 0.663 (Fig. 1). Applying the methods of phylogenetic analysis for comparing trees (Wojcicki and Brooks 2005), geographic locations, highlighted

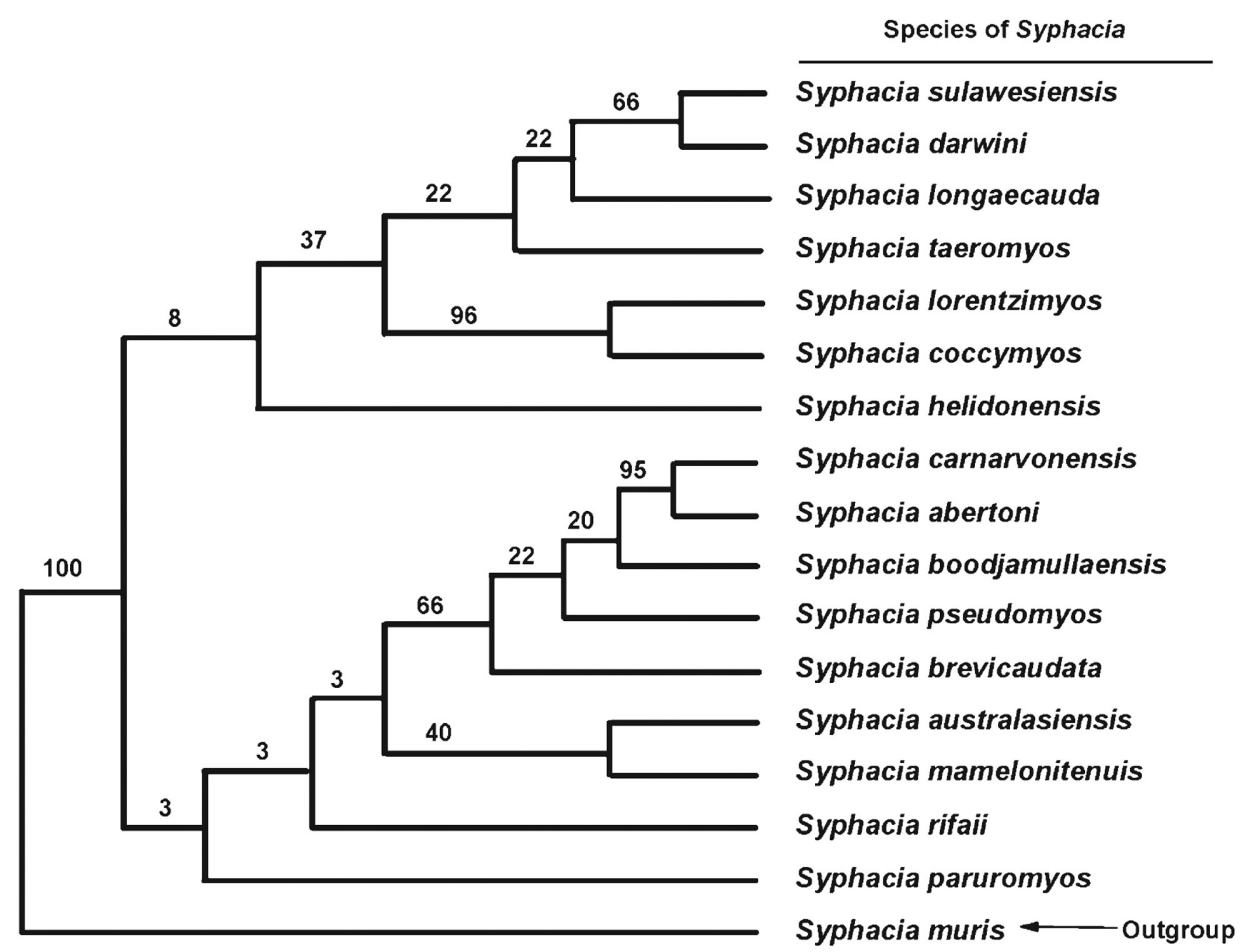

Fig. 1. Single most parsimonious tree produced by implicit enumeration in TNT (one tree was produced) with a length of 44.356 , a consistency index of 0.521 and a retention index of 0.633 . Symmetric resampling support values, shown above branches, were calculated with 1000 replicates completed. 


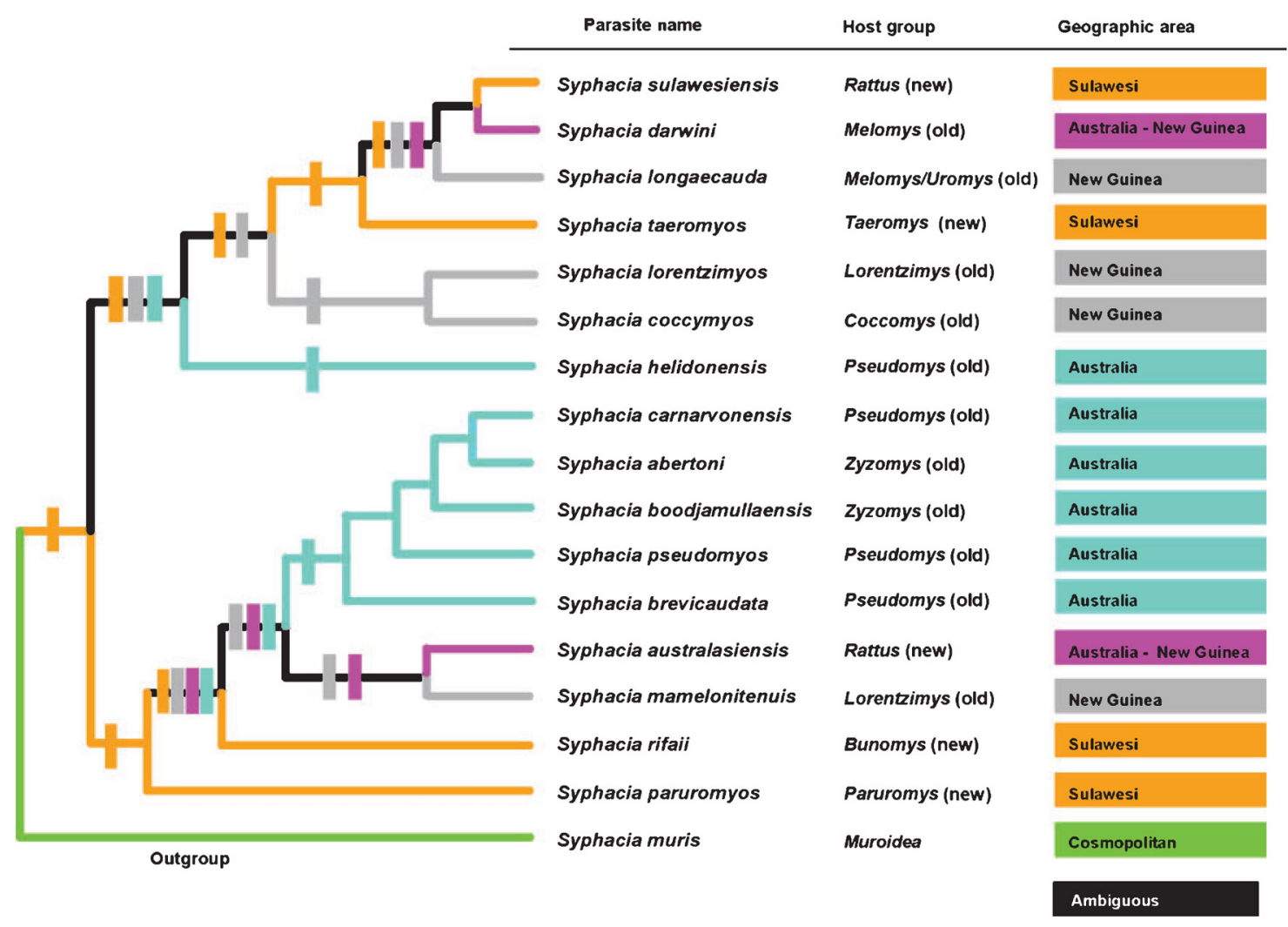

Fig. 2. Tree with geographic areas optimized (in color) shows clear evidence that Sulawesi represents the ancestral geographic area of species of Syphacia. Colors and marks on tree indicate the corresponding geographic area, generic names under 'host group' indicate the genus of host, and the designation 'old' = rodents of the tribe Hydromyini, 'new' = rodents of the tribe Rattini.

in color, and host genera, indicated in text, for each species of parasite, were added to the phylogenetic tree (Fig. 2). Farris optimization indicated that Sulawesi was the ancestral area for species of Syphacia in the Australian Bioregion (orange) with subsequent diversification into two main clades of Syphacia followed by losses, incomplete sampling, or differential invasions of these pinworms across the region. The clades of species of Syphacia in this analysis showed loose associations that appear to reflect both the evolutionary diversification and biogeographic affinities of their hosts. For example, five of the species of Syphacia from old endemic Australian mammals (genera Zyzomys and Pseudomys) form a clade on the tree. However, the biogeographic and evolutionary relationships of some host-parasite associations shown here do not appear correlated, and there were mixtures 
of taxa from different hosts. For example, S. sulawesiensis Hasegawa \& Tarore, 1996 from $R$. xanthurus (a new endemic), shares a common ancestor with $S$. darwini, a species from Australia and New Guinea that parasitizes species of Melomys (an old endemic). The other taxa sharing ancestral host species include $S$. longaecauda Smales, 2001 from New Guinea and S. taeromyos Dewi \& Hasegawa, 2014 from a new endemic rodent in Sulawesi.

The diversification of Syphacia on the Australian continent indicates in situ speciation in the old endemic rodent hosts. By adding the geographic areas where the parasites and their hosts are found to the tree (Fig. 2), we found that most species of Syphacia from the Australian continent had an origin in Sulawesi with a clear diversification of S. brevicaudata Weaver \& Smales, 2008, S. pseudomyos Weaver \& Smales, 2008, S. boodjamullaensis Weaver \& Smales, 2010, S. abertoni Weaver \& Smales 2006, and S. carnarvonensis Weaver \& Smales, 2010 on the Australian continent. The sister taxa, S. australasiensis Smales, 2004 and $S$. mamelonitenuis Smales, 2010, originated from the ancestor that gave rise to the clade found only in Australia, with $S$. mamelonitenuis restricted to New Guinea and $S$. australasiensis occurring in species of Rattus in both New Guinea and Australia.

\section{Discussion}

\section{Phylogenetic analysis}

Data mining (Wu et al. 2003) of useful phylogenetic information from published descriptive material has inherent problems in that for many (not all) species descriptions (ranging from worms to birds) authors do not provide full estimates of statistical measures of central tendency (Sokal and Rohlf 1981), which would be ideal in these types of analyses. The method we developed here was devised to provide intervals that were estimated using mean and maximum values in a manner that would be coded with the same state as an interval that included the complete range of values for a quantitative character. This method maximizes the usefulness of descriptive data that exist in large quantities in the literature as well as mensural data taken from specimens from museum collections that may have few representatives. 
We used morphological data to estimate a phylogeny based on maximum parsimony using the program TNT, which is the only phylogenetics program based on parsimony that allows a user to analyze both discrete and continuous characters simultaneously via a single input matrix (Goloboff et al. 2006, 2008). From the beginning of the phylogenetic revolution in systematic biology that started in the late 1960 s (Hull 1988), biologists interested in estimating phylogenetic trees lamented the lack of a robust and objective method of coding continuous characters for tree construction (see examples in Farris 1972; Archie 1985; Gardner 1991; Monks 2001). To solve the problem of using continuous/mensural characters in cladistic analyses, several authors proposed methods of coding that converted these characters into discrete units suitable for phylogenetic analyses (Farris 1970, 1972; Felsenstein 1982; Archie 1985; Goloboff et al. 2008). Goloboff et al. (2006) applied the use of the Farris Transform (Farris 1972) in the implementation of TNT and this provided a much needed mechanism to enable the recovery of phylogenetic information inherent in continuous characters. We have applied these principles to our analysis to interpret our dataset.

The three currently accepted methods used to generate Hennigian (phylogenetic) trees are maximum parsimony, maximum likelihood, and Bayesian likelihood. Brooks et al. (2007) showed that all three methods produce similar results when Hennig's auxiliary criterion is applied and outgroup rooting is employed. The outcome was the same regardless of the kinds of data analyzed and, if there were any discrepancies, application of additional data (derived from study of more specimens) was shown to resolve them. Because of the restrictions of data-input types in other mainstream programs, and because recent work has shown that these main methods converge to the same answers given enough input data (Brooks et al. 2007), TNT was determined to be the best phylogenetics program for our particular dataset. In our analysis, we logn-transformed continuous characters and used them in runs of TNT (with the Farris Transform, e.g. Farris 1970; Dress et al. 2007) along with simultaneous use of both multistate and binary characters (all in the same matrix: see Goloboff et al. 2008). We chose this combination of characters for the increased precision that continuous characters provide against simple binary characters. This method alleviates the problem of coding characters using 
qualitative estimates like: longer than/shorter than, or ratios of characters using bigger than/smaller than. This also eliminates the problem of correlated characters that arise immediately when ratios are used that are, of course, composed of completely correlated characters.

\section{Biogeography and divergence of rodents in the Australian Bioregion}

Most species of pinworms, especially those occurring in primates, are presumed by past authors to have cospeciated with their hosts, thus showing a more or less one to one host-parasite relationship (Hugot 1988). While some trends are evident in our analysis (between closely related Syphacia spp. and shared host genera, e.g. between species of Pseudomys), the analysis also shows no relationship between some species from rodents from the islands of New Guinea and Sulawesi. The weakness in the trends of parasites from hosts from these islands may be a reflection of the multiple radiations and complicated systematic relationships among the endemic rodents of the region. Species in the genus Uromys are thought to have diverged from other New Guinea rodents around 3 million years ago, with species of Melomys diversifying later ( 2.1 million years ago) (Bryant et al. 2011). The genus Melomys appears to have undergone very recent speciation, and the exact relationships between Australian and New Guinean species are still unresolved (Bryant et al. 2011). The Zyzomys/ Pseudomys clade, on the other hand, is an Australian-derived radiation that is estimated to have diversified from old endemics from New Guinea around 5.5 to 5.1 million years ago and radiated across most of Australia (Rowe et al. 2008). The diversification of the new endemic tribe Rattini is interesting from a coevolutionary perspective, with at least three colonizations of Sulawesi occurring during the Miocene (including the genera Bunomys and Rattus) (Fabre et al. 2013). The Australo-Papuan lineage of Rattus is thought to have diverged around 2.7 million years ago (Robins et al. 2010). This lineage has an extremely fast rate of diversification across Australia and New Guinea (Rowe et al. 2011), and the resulting species have often found niches alongside species of Melomys or other hydromyin genera, where they occur in sympatry.

The clade representing species of Syphacia occurring on the continent of Australia are not characterized by strict cospeciation with 
their hosts. The host-parasite associations observed appear to be an excellent example of the combined effect of taxon pulses and EF; both of which are elements of the Stockholm Paradigm. Expansion or invasion of rodents to new geographic areas during time of improved access due to low water (glaciation events) affecting the archipelago of Malaysia/Indonesia and the Australian continent produced taxon pulses that influenced extant parasite assemblages. With numerous glacial cycles (up to 20) during the Pleistocene (Voris 2000), the sea level fluctuations may have facilitated such pulses of speciation, even in land that remained islands (e.g. Sulawesi) as rafting rodents could have crossed less water to colonize new land.

Parasite speciation and host-specificity in the Australian Bioregion

The presence of one species of Syphacia in multiple species of host in the region appears to be a result of EF, indicating that species of $S y$ phacia switched from one host species to another (without speciation) during a period of ecological or syntopic (cf. Rivas 1964) overlap among rodent host species. Exploiting a new host that is closely related to an existing host species (thus providing similar habitat) would mean that the parasite would lose nothing by adapting to the new host species, as the parasite sees the host as a plesiomorphic ecological habitat and can use the resource directly. Ecological Fitting broadens potential host opportunities over space and time. In our analysis, the most parsimonious explanation of multiple species of pinworms in rodents, and multiple host species of a pinworm species, would be that EF provides the most benefits with very low (if any) evolutionary cost. In the Australian Bioregion, however, there does appear to be a relatively high degree of host-specificity for Syphacia species, with only four different species being recorded from more than one host rodent species. Syphacia rifaii Dewi \& Hasegawa, 2010 was recorded from two species of Bunomys in Sulawesi, and $S$. brevicaudata has been recorded from two co-occurring species of Pseudomys in Australia (Weaver and Smales 2008; Dewi and Hasegawa 2010). Syphacia longaecauda has the longest host list, with records from several species of Melomys, and Uromys anak Thomas, 1907, but all from New Guinea (Smales 2001, 2009; Smales and Spratt 2008). Moreover, $S$. darwini has been recorded from several species of Melomys from both 
Australia and New Guinea. The few species of Syphacia that have been recorded from more than one host appear to still be restricted to the same host genus (except for $S$. longaecauda, although the host genera Melomys and Uromys are considered sister clades (Geffen et al. 2011), indicating that where switching has occurred, it is most likely to be because of EF.

Furthermore, we must consider how a single rodent species may be host to more than one species of Syphacia. Many rodent species have highly disjunct distributions, with very little or no contact between individuals of the same species between different populations. Depending on the length of time that the populations have been separated, additional opportunities for in-host speciation of parasites may have occurred, where different species occupy the same niche in geographically isolated hosts. For example, Z. argurus (Thomas, 1889) is host to $S$. abertoni in inland Queensland and Northern Territory, but also hosts $S$. boodjamullaensis in north-western coastal Queensland. The populations of $Z$. argurus that host the two Syphacia species are geographically disjunct, and our analysis indicates that the two parasite species are not sister taxa but they did share a common ancestor after switching from Pseudomys to Zyzomys and then making what looks like a host-switch back to Pseudomys.

While host-specificity has been hypothesized to be a general characteristic of the Syphaciini (see Hugot and Quentin 1985; Hugot 1988), the geographic ranges of species of host rodents are often sympatric, providing the potential for EF. Despite the numerous hypothesized rodent-dispersal events between Australia and New Guinea, two groups (the new endemic $R$. leucopus (Gray, 1867), and members of the old endemic hydromyin genera Melomys and Uromys), occur widely throughout northern parts of Australia and across New Guinea. It appears that pulses of speciation of these two groups occurred separately (both spatially and temporally), which would produce the patterns shown in Figs 1 and 2 (Hoberg and Brooks 2010). Syphacia australasiensis (from $R$. leucopus) and S. darwini (from Melomys spp.) have both been collected from hosts in Australia and New Guinea. One, S. darwini, has successfully switched to multiple host species, yet there is no evidence yet that $S$. australasiensis has switched. Given the degree of sympatry and co-occurrence of species of Melomys in both New Guinea and Australia, compared with that of the species of 
Rattus in New Guinea, the distribution of $S$. darwini may be the result of EF, but the wide distribution of $S$. australasiensis in populations of one host species only is not. In studies of Syphacia species from Japan, Okamoto et al. (2009, 2007) found little agreement in the phylogeny of the species of Syphacia alongside the biogeography of their rodent hosts, and suggested that perhaps EF was more common in Syphacia species than previously thought.

Biogeography of Syphacia species and next steps

Our results indicate that both taxon pulses and EF are the likely mechanisms underpinning the biogeography of species of Syphacia in the Australian Bioregion. An important caveat for our results is the effect of sampling effort on the specimens we were able to examine. The helminth fauna for many Australo-Papuan rodent species is either unknown or incompletely known (Smales 1997, 2012). Our analysis here provides a comprehensive, but not exhaustive suite of taxa, and we acknowledge that it will never be 'complete', with new species of $S y$ phacia continuing to be discovered and described. Examples include S. semiadii Dewi, Asakawa \& Fitriana, 2014 and S. maxomyos Dewi, Hasegawa, Fitriana \& Asakawa, 2015, both described from Indonesian rodents (Dewi et al. 2014, 2015), but these taxa were not able to be included in this present analysis. Advances in understanding the helminth diversity of rodents would contribute extra data to provide greater resolution for phylogenetic and biogeographic studies, and assist in testing the hypothesis of EF in Syphacia species in the area.

An additional approach to expand on this research would be to use molecular tools to augment and provide additional data to shed more light on the phylogenetic relationships among species of Syphacia. That would require collecting new material (either through examination of rodent voucher specimens in museums, or trapping) for most, if not all, of the species currently recognized in the genus Syphacia in the Australian Bioregion as many were collected using fixation methods that preserve genetic material poorly, if at all. The objective method of using molecular data to estimate relationships can provide an important complement to the use of morphological data. The primary reason to use these kinds of additional data in these analyses is to increase the number of characters and to test homologies because, 
as Hennig (1966) stated so well, 'homology covaries with phylogeny'.

In conclusion, we examined the phylogeny of species of Syphacia from the Australian Bioregion from different theoretical perspectives, with the aim of developing a new understanding of possible evolutionary relationships. We found that while some species of Syphacia had reasonably close host-parasite associations, others did not. We also found that our distribution of species supports the hypothesis for multiple pulses of speciation and expansion of rodents across the Australian Bioregion, but that their parasites are not exclusively bound to them in the strict sense of co-speciation. This indicates that the theories of both taxon pulses and EF explain the biogeographic distribution of extant species of Syphacia.

Acknowledgments Thanks to Lesley Warner for discussions and supervision of an earlier version of this dataset. Thanks to Gabor Racz, Sue Ann Gardner for editing, and to Dan R. Brooks and Philip Barton for reading drafts of the manuscript. We also extend thanks to Pablo Goloboff for valuable discussion on the use of continuous data in phylogenetic reconstruction in TNT. This work was facilitated by a travel grant from the Australian Society for Parasitology (to HJW).

\section{References}

Adamson, M. (1994). Evolutionary patterns in life histories of Oxyurida. International Journal for Parasitology 24, 1167-1177. http://dx.doi. org/10.1016/0020-7519(94)90189-9

Anderson, R. (2000). 'Nematode Parasites of Vertebrates: their Development and Transmission.' (CAB International: Oxford.)

Archie, J. W. (1985). Methods for coding variable morphological features for numerical taxonomic analysis. Systematic Biology 34, 326-345. http://dx.doi. org/10.1093/sysbio/34.3.326

Brooks, D., and McLennan, D. (2002). 'The Nature of Diversity: an Evolutionary Voyage of Discovery.' (Chicago University Press: Chicago.)

Brooks, D., and McLennan, D. (2003). Extending phylogenetic studies of coevolution: secondary Brooks parsimony analysis, parasites and the Great Apes. Cladistics 19, 104-119. http://dx.doi.org/10.1111/j.1096-0031.2003. tboo298.x

Brooks, D., Leon-Regagnon, V., McLennan, D., and Zelmer, D. (2006). Ecological fitting as a determinant of the community structure of platyhelminth parasites of anurans. Ecology 87(Suppl.), S76-S85. http://dx.doi. org/10.1890/0012-9658(2006)87[76:EFAADO]2.0.CO;2 
Brooks, D., Bilewitch, J., Charmaine, C., Evans, D., Folinsbee, K., Frobisch, J., Halas, D., Hill, S., McLennan, D., Mattern, M., Tsuji, L., Ward, J., Wahlberg, D., and Zanatta, D. (2007). Quantitative phylogenetic analysis in the 21st century. Revista Mexicana de Biodiversidad 78, 225-252.

Brooks, D. R., Hoberg, E. P., Boeger, W. A., Gardner, S. L., Galbreath, K. E., Herczeg, D., Mejía-Madrid, H. H., Rácz, E., and Dursahinhan, A. T. (2014). Finding them before they find us: informatics, parasites and environments in accelerating climate change. Comparative Parasitology 81, 155-164. http:// dx.doi.org/10.1654/4724b.1

Brooks, D. R., Hoberg, E. P., and Boeger, W. A. (2015). In the eye of the cyclops: the classic case of cospeciation and why paradigms are important. Comparative Parasitology 82, 1-8. http://dx.doi.org/10.1654/4724C.1

Bryant, L., Donnellan, S., Hurwood, D., and Fuller, S. (2011). Phylogenetic relationships and divergence data estimates among Australo- Papuan mosaictailed rats from the Uromys division (Rodentia: Muridae). Zoologica Scripta 40, 433-447. http://dx.doi.org/10.1111/j.1463-6409.2011.00482.x

Cameron, T. (1929). The species of Enterobius Leach in primates. Journal of Helminthology 7, 161-182. http://dx.doi.org/10.1017/So022149X00018770

Cox, B. (2001). The biogeographic regions reconsidered. Journal of Biogeography 28, 511-523. http://dx.doi.org/10.1046/j.1365-2699.2001.00566.x

Dewi, K., and Hasegawa, H. (2010). A new Syphacia species (Nematoda: Oxyuridae) collected from Bunomys spp. (Rodentia: Muridae) in central Sulawesi, Indonesia. The Journal of Parasitology 96, 125-128. http://dx.doi. org/10.1645/GE-2152.1

Dewi, K., and Hasegawa, H. (2014). Two new species of Syphacia (Nematoda: Oxyuridae) in endemic murid rodents from Sulawesi, Indonesia. Journal of Helminthology 88, 41-49. http://dx.doi.org/10.1017/So022149X12000703

Dewi, K., Asakawa, M., and Fitriana, Y. S. (2014). Syphacia (Syphacia) semiadii n. sp. (Nematoda: Oxyuridae) from Halmaheramys bokimekot Fabre et al., 2013 (Rodentia: Muridae) on Halmahera Island, Indonesia. Transactions of the Royal Society of South Australia 138, 98-104. http://dx.doi.org/10.1080/03721426.2 014.10887193

Dewi, K., Hasegawa, H., Fitriana, Y. S., and Asakawa, M. (2015). Syphacia (Syphacia) maxomyos sp. n. (Nematoda: Oxyuridae) from Maxomys spp. (Rodentia: Muridae) from Sulawesi and Sumatra, Indonesia. The Journal of Veterinary Medical Science 77, 1217-1222. http://dx.doi.org/10.1292/ jvms.14-0659

Dress, A., Huber, K. T., and Moulton, V. (2007). Some uses of the Farris Transform in mathematics and phylogenetics - a review. Annals of Combinatorics 11, 1-37. http://dx.doi.org/10.1007/s00026-007-0302-5

Erwin, T. (1985). The taxon pulse: a general pattern of lineage radiation and extinction among carabid beetles. In 'Taxonomy, Phylogeny and Biogeography of Beetles and Ants'. (Ed. G. Ball.) pp. 437-472. (W. Junk: Dordrecht.) 
Fabre, P.-H., Pages, M., Musser, G., Fitriana, Y., Fjeldsa, J., Jennings, A., Jonsson, K., Kennedy, J., Michaux, J., Semiadi, G., Supriatna, N., and Helgen, K. (2013). A new genus of rodent from Wallacea (Rodentia: Muridae: Murinae: Rattini), and its implication for biogeography and Indo-Pacific Rattini systematics. Zoological Journal of the Linnean Society 169, 408-447. http://dx.doi. org/10.1111/zoj.12061

Farris, J. (1970). Methods for computing Wagner trees. Systematic Zoology 19, 83-92. http://dx.doi.org/10.2307/2412028

Farris, J. (1972). Estimating phylogenetic trees from distance matrices. American Naturalist 106, 645-668. http://dx.doi.org/10.1086/282802

Felsenstein, J. (1982). Numerical methods for inferring evolutionary trees. The Quarterly Review of Biology 57, 379-404. http://dx.doi.org/10.1086/412935 Flannery, T. (1995). 'The Mammals of New Guinea.' (Reed Books: Sydney.)

Gardner, S. L. (1991). Phyletic coevolution between subterranean rodents of the genus Ctenomys (Rodentia: Hystricognathi) and nematodes of the genus Paraspidodera (Heterakoidea: Aspidoderidae) in the Neotropics: temporal and evolutionary implications. Zoological Journal of the Linnean Society 102, 169201. http://dx.doi.org/10.1111/j.1096-3642.1991.tboo288.x

Geffen, E., Rowe, K., and Yom-Tov, Y. (2011). Reproductive rates in Australian rodents are related to phylogeny. PLoS One 6(4), e19199. http://dx.doi. org/10.1371/journal.pone.0019199

Goloboff, P., Mattoni, C., and Quinteros, Y. (2006). Continuous characters analyzed as such. Cladistics 22, 589-601. http://dx.doi. org/10.1111/j.1096-0031.20 06.00122.X

Goloboff, P. A., Farris, J. S., and Nixon, K. C. (2008). TNT, a free program for phylogenetic analysis. Cladistics 24, 774-786. http://dx.doi. org/10.1111/j.1096-0031.2008.00217.x

Halas, D., Zamparo, D., and Brooks, D. (2005). A historical biogeographical protocol for studying biotic diversification by taxon pulses. Journal of Biogeography 32, 249-26o. http://dx.doi.org/10.1111/j.1365-2699.2004.01147.x

Hasegawa, H., and Tarore, D. (1996). Syphacia (Syphacia) sulawesiensis n. sp. and S. (S.) muris (Yamaguti 1935) (Nematoda: Oxyuridae) collected from Rattus xanthurus (Gray 1867) (Rodentia: Muridae) in north Sulawesi, Indonesia. Tropical Zoology 9, 165-173. http://dx.doi.org/10.1080/03946975.1996.10539 305

Hennig, W. (1966). 'Phylogenetic Systematics.' (University of Illinois Press: Urbana, IL.)

Hoberg, E., and Brooks, D. (2010). Beyond vicariance: integrating taxon pulses, ecological fitting and oscillation in evolution and historical biogeography. In 'The Biogeography of Host-Parasite Interactions'. (Eds. S. Morand and B. Krasnov.) pp. 7-15. (Oxford University Press: Oxford.)

Hoberg, E. P., and Brooks, D. R. (2015). Evolution in action: climate change, biodiversity, dynamics and emerging infectious diseases. Philosophical Transactions of the Royal Society of London. Series B, Biological Sciences 370, 20130553. http://dx.doi.org/10.1098/rstb.2013.0553 
Holt, B., Lessard, J.-P., Borregaard, M., Fritz, S., Araujo, M., Dimitrov, D., Fabre, P.H., Graham, C., Graves, G., Jonsson, K., Nogues-Bravo, D., Wang, Z., Whittaker, R., Fjeldsa, J., and Rahbek, C. (2013). An update of Wallace's zoogeographic regions of the world. Science 339, 74-78. http://dx.doi.org/10.1126/ science. 1228282

Hugot, J.-P. (1988). Les nematodes Syphaciinae parasites de rongeurs et de lagomorphes: taxonomie, zoogeographie, evolution. Memoires du Museum National d'Histoire Naturelle 141, 1-148.

Hugot, J.-P. (1990). The Syphaciinae (Oxyuridae, Nematoda) parasitic in rodents and lagomorphs. Numerical taxonomy, cladistic analysis of evolution. Annales de Parasitologie Humaine et Comparee 65(Suppl. 1), 27-29.

Hugot, J.-P. (1999). Primates and their pinworm parasites: the Cameron hypothesis revisited. Systematic Biology 48, 523-546. http://dx.doi. org/10.1080/106351599260120

Hugot, J.-P., and Quentin, J.-C. (1985). Étude morphologique de six espèces nouvelles ou peu connues appartenant au genre Syphacia (Oxyuridae, Nematoda), parasites de Rongeurs Cricétidés et Muridés. Bulletin du Muséum National d'Histoire Naturelle 4, 383-400.

Hugot, J.-P., Gardner, S., and Morand, S. (1996). The Enterobiinae subfam. nov. (Nematoda: Oxyuridae) pinworm parasites of primates and rodents. International Journal for Parasitology 26, 147-159. http://dx.doi. org/10.1016/0020-7519(95)00108-5

Hugot, J.-P., Feliu, C., Douangboupha, B., and Ribas, A. (2013). Laoxyuris laonasti n. gen., n. sp. (Nematoda: Syphaciinae) parasite of Laonastes aenigmamus (Rodentia: Diatomyidae): morphology, biology, taxonomy, phylogeny. Infection, Genetics and Evolution 16, 113-121. http://dx.doi.org/10.1016/j. meegid.2013.01.003

Hull, D. L. (1988). 'Science as a Process: an Evolutionary Account of the Social and Conceptual Development of Science.' (University of Chicago Press: Chicago.)

Janz, N., and Nylin, S. (2008). The oscillation hypothesis of host plant range and speciation. In 'Specialization, Speciation and Radiation: the Evolutionary Biology of Herbivorous Insects'. (Ed. K. J. Tilmon.) pp. 203-215. (University of California Press: Berkeley.)

Janzen, D. (1985). On ecological fitting. Oikos 45, 308-310. http://dx.doi. org/10.2307/3565565

Lecompte, E., Aplin, K., Denys, C., Catzeflis, F., Chades, M., and Chevret, P. (2008). Phylogeny and biogeography of African Murinae based on mitochondrial and nuclear gene sequences, with a new tribal classification of the subfamily. BMC Evolutionary Biology 8, 199. http://dx.doi.org/10.1186/1471-2148-8-199

Long, J., Archer, M., Flannery, T., and Hand, S. (2002). 'Prehistoric Mammals of Australia and New Guinea: One Hundred Million Years of Evolution.' Johns Hopkins University Press: Baltimore, MD.

Monks, S. (2001). Phylogeny of the Acanthocephala based on morphological characters. Systematic Parasitology 48, 81-115. http://dx.doi. org/10.1023/A:1006400207434 
Nilsson, M., Harlid, A., Kullberg, M., and Janke, A. (2010). The impact of fossil calibrations, codon positions and relaxed clocks on the divergence time estimates of the native Australian rodents (Conilurini). Gene 455, 22-31. http://dx.doi.org/10.1016/j.gene.2010.02.002

Okamoto, M., Urushima, H., Iwasa, M., and Hasegawa, H. (2007). Phylogenetic relationships of rodent pinworms (genus Syphacia) in Japan inferred from mitochondrial CO1 gene sequences. The Journal of Veterinary Medical Science 69, 545-547. http://dx.doi.org/10.1292/jvms.69.545

Okamoto, M., Urushima, H., and Hasegawa, H. (2009). Phylogenetic relationships of rodent pinworms (genus Syphacia) in Japan inferred from $28 \mathrm{~S}$ rDNA sequences. Parasitology International 58, 330-333. http://dx.doi.org/10.1016/j. parint.2009.07.001

Petter, A., and Quentin, J.-C. (1976). 'CIH Keys to the Nematode Parasites of Vertebrates. No 4. Keys to the Genera of the Oxyuroidea.' (CAB: London.)

Quentin, J.-C. (1971). Morphologie comparée des structures céphaliques et génitales des oxyures de genre Syphacia. Annals Parasitologie Humaine et Comparée 46, 15-60.

Rivas, L. (1964). A reinterpretation of the concepts 'sympatric' and 'allopatric' with proposal of the additional terms 'syntopic' and 'allotopic'. Systematic Zoology 13, 42-43. http://dx.doi.org/10.2307/2411436

Robins, J., McLenachen, P., Phillips, M., McComish, B., Matisoo-Smith, E., and Ross, H. (2010). Evolutionary relationships and divergence times among the native rats of Australia. BMC Evolutionary Biology 10, 375.

Rowe, K., Reno, M., Richmond, D., Adkins, R., and Steppan, S. (2008). Pliocene colonization and adaptive radiations in Australia and New Guinea (Sahul): multilocus systematics of the old endemic rodents (Muroidea: Murinae). Molecular Phylogenetics and Evolution 47, 84-101. http://dx.doi.org/10.1016/j. ympev.2008.01.001

Rowe, K., Aplin, K., Baverstock, P., and Moritz, C. (2011). Recent and rapid speciation with limited morphological disparity in the genus Rattus. Systematic Biology 6o, 188-203. http://dx.doi.org/10.1093/sysbio/syqog2

Sclater, P. L. (1858). On the general geographical distribution of the members of the class Aves. Journal of the Proceedings of the Linnean Society of London. Zoology 2, 130-136. http://dx.doi.org/10.1111/j.1096-3642.1858.tbo2549.x

Smales, L. R. (1992). A survey of the helminths of Rattus sordidus, the canefield rat, together with a description of Ancistronema coronatum n. gen., n. sp. (Nematoda: Chabertiidae). Systematic Parasitology 22, 73-80. http://dx.doi. org/10.1007/BFoo009637

Smales, L. R. (1997). A review of the helminth parasites of Australian rodents. Australian Journal of Zoology 45, 505-521. http://dx.doi.org/10.1071/ZO97013

Smales, L. R. (2001). Syphacia longaecauda n. sp. (Nematoda: Oxyuridae) Syphacinea from Melomys spp. (Muridae: Hydromyinae) from Papua New Guinea and Irian Jaya, Indonesia. Parasite 8, 39-43. http://dx.doi.org/10.1051/ parasite/2001081039 
Smales, L. R. (2004). Syphacia (Syphacia) australiasiensis sp. nov. (Nematoda: Oxyuridae) from Rattus leucopus (Muridae) from Papua New Guinea and Australia. Transactions of the Royal Society of South Australia 128, 47-51.

Smales, L. R. (2005). Helminth parasites of the grassland melomys (Muridae: Hydromyinae) from Australia and Papua New Guinea. Australian Journal of Zoology 53, 369-374. http://dx.doi.org/10.1071/Z005039

Smales, L. R. (2009). Helminths of Melomys rufescens and Melomys spp. (Muridae: Hydromyinae) from Papua New Guinea with the descriptions of a new genus and five new species in the Heligmonellidae (Nematoda: Trichostrongyloidea). The Raffles Bulletin of Zoology 57, 5-15.

Smales, L. R. (2010). The gastrointestinal helminths of Lorentzimys nouhuysi (Rodentia: Muridae) with descriptions of two new genera and three new species (Nematoda) from Papua New Guinea. The Journal of Parasitology 96, 6o2-613. http://dx.doi.org/10.1645/GE-2243.1

Smales, L. R. (2011). Gastrointestinal nematodes of Coccymys ruemmleri (Rodentia, Muridae) with the description of Montistrongylus giluwensis sp. nov. (Heligmonellidae) and Syphacia coccymyos sp. nov. (Oxyuridae) from Papua New Guinea. Acta Parasitologica 56, 418-426. http://dx.doi. org/10.2478/s11686-011-0067-1

Smales, L. R. (2012). Helminth parasites of hydromyine rodents from the island of New Guinea. In 'Rodents: Habitat, Pathology and Environmental Impact'. (Eds. A. Triunveri, and D. Scalise.) pp. 99-117. (Nova Science Publishers: New York.)

Smales, L. R., and Spratt, D. M. (2008). Helminth assemblages of Uromys spp. (Muridae: Hydromyinae) from Australia, Papua New Guinea and Papua Indonesia and comparison with assemblages in Melomys spp. Australian Journal of Zoology 56, 85-94. http://dx.doi.org/10.1071/ZOo8011

Sokal, R. R., and Rohlf, F. J. (1981). 'Biometry: the Principles and Practice of Statistics in Biological Research.' 2nd edn. (W.H. Freeman and Co.)

Sorci, G., Morand, S., and Hugot, J.-P. (1997). Host-parasite coevolution: comparative evidence for covariation of life history traits in primates and oxyurid parasites. Proceedings of the Royal Society B: Biological Science 264, 285-289.

Thompson, J. N. (2005). 'The Geographic Mosaic of Coevolution.' (University of Chicago Press: Chicago.)

Van Dyck, S., and Strahan, R. (Eds.) (2008). 'Mammals of Australia.' (Reed New Holland: Sydney.)

van Welzen, P., Turner, H., and Roos, M. (2001). New Guinea: a correlation between accreting areas and dispersing Sapindaceae. Cladistics 17, 242-247. http://dx.doi.org/10.1006/clad.2001.0173

Voris, H. (2000). Maps of Pleistocene sea levels in southeast Asia: shorelines, river systems and time durations. Journal of Biogeography 27, 1153-1167. http://dx.doi.org/10.1046/j.1365-2699.2000.00489.x

Wallace, A. (1876). 'The Geographical Distribution of Animals.' (Macmillan: London.) 
Watrous, L., and Wheeler, Q. (1981). The outgroup comparison method of character analysis. Systematic Biology 30, 1-11. http://dx.doi.org/10.1093/ sysbio/30.1.1

Watts, C., and Aslin, H. (1981). 'The Rodents of Australia.' (Angus and Robertson: Australia.)

Weaver, H. J., and Smales, L. R. (2006). Syphacia (Syphacia) abertoni n. sp. (Nematoda: Oxyuridae) from Zyzomys argurus (Thomas) (Rodentia: Muridae) from northern Australia. Transactions of the Royal Society of South Australia 131, 206-210.

Weaver, H. J., and Smales, L. R. (2008). New species of Syphacia (Syphacia) Seurat (Nematoda: Oxyuridae) from Pseudomys species (Rodentia: Muridae) from central Australia. Zootaxa 1775, 39-50. http://dx.doi.org/10.11646/ zootaxa.1775.1.3

Weaver, H. J., and Smales, L. R. (2010). Three new species of Syphacia (Syphacia) (Oxyurida: Oxyuridae) from Queensland, Australia and a key to the species present in the Australian Bioregion. Comparative Parasitology 77, 9-19. http:// dx.doi.org/10.1654/4405.1

Wojcicki, M., and Brooks, D. (2005). PACT: an efficient and powerful algorithm for generating area cladograms. Journal of Biogeography 32, 755-774. http:// dx.doi.org/10.1111/j.1365-2699.2004.01148.x

Wu, Y., Wang, X., Liu, X., and Wang, Y. (2003). Data-mining approaches reveal hidden families of proteases in the genome of malaria parasite. Genome Research 13, 601-616. http://dx.doi.org/10.1101/gr.913403

Yamaguti, S. (1935). Studies on the helminth fauna of Japan. Part 13: Mammalian nematodes. Japanese Journal of Zoology 6, 433-457. 